\title{
GLP-1 (7-36) amide restores myocardial insulin sensitivity and prevents the progression of heart failure in senescent beagles
}

\author{
Melissa Chen ${ }^{1}$, Franca S Angeli ${ }^{1}$, You-tang Shen ${ }^{1}$ and Richard P Shannon ${ }^{1,2,3^{*}}$
}

\begin{abstract}
Background: We previously demonstrated that older beagles have impaired whole body and myocardial insulin responsiveness (MIR), and that glucagon-like peptide-1 (GLP-1 [7-36] amide) improves MIR in young beagles with dilated cardiomyopathy (DCM). Here, we sought to determine if aging alone predisposes to an accelerated course of DCM, and if GLP-1 [7-36] amide would restore MIR and impact the course of DCM in older beagles.

Methods: Eight young beagles (Young-Control) and sixteen old beagles underwent chronic left ventricle (LV) instrumentation. Seven old beagles were treated with GLP-1 (7-36) amide $(2.5 \mathrm{pmol} / \mathrm{kg} / \mathrm{min})$ for 2 weeks prior to instrumentation and for 35 days thereafter (Old + GLP-1), while other 9 served as control (Old-Control). All dogs underwent baseline metabolic determinations and LV biopsy for mitochondria isolation prior to the development of DCM induced by rapid pacing $\left(240 \mathrm{~min}^{-1}\right)$. Hemodynamic measurements were performed routinely as heart failure progressed.
\end{abstract}

Results: At baseline, all old beagles had elevated non-esterifed fatty acids (NEFA), and impaired MIR. GLP-1 reduced plasma NEFA (Old-Control: $853 \pm 34$; Old + GLP-1: $531 \pm 33 \mu \mathrm{mol} / \mathrm{L}, \mathrm{p}<0.02$ ), improved MIR (Old-Control: $289 \pm 54$; Old + GLP-1: $512 \pm 44$ mg/min/100 mg, p < 0.05), and increased uncoupling protein-3 (UCP-3) expression in isolated mitochondria. Compared to the Young-Control, the Old-Controls experienced an accelerated course of DCM (7 days versus 29 days, $p<0.005)$ and excess mortality, while the Old + GLP-1 experienced increased latency to the onset of DCM (7 days versus 23 days, $p<0.005$ ) and reduced mortality.

Conclusion: Aging is associated with myocardial insulin resistance, which predispose to an accelerated course of DCM. GLP-1 treatment is associated with increased MIR and protection against an accelerated course of DCM in older beagles.

Keywords: Glucagon-like pepetide-1, Dilated cardiomyopathy, Myocardial insulin resistance, Aging

\section{Introduction}

The aging population in the western world continues to be burdened by a disproportionate share of cardiovascular $(\mathrm{CV})$ disease and the morbidity and mortality of cardiovascular conditions such as heart failure is increased among the elderly $[1,2]$. Cardiovascular risk factors such as hypertension and diabetes accrue in older populations contributing to the increased burden of $\mathrm{CV}$ disease.

\footnotetext{
* Correspondence: rs3mt@virginia.edu

${ }^{1}$ Departments of Medicine, University of Pennsylvania Perelman School of Medicine, Philadelphia, PA, USA

${ }^{2}$ Department of Medicine, University of Virginia School of Medicine,

Philadelphia, PA, USA

Full list of author information is available at the end of the article
}

However, it remains uncertain as to how much of the burden is a consequence of these recognized risk factors and how much is attributable to aging alone [3].

Prior studies from our laboratory have demonstrated that aging in beagles is associated with the development of both whole body and myocardial insulin resistance, independent of obesity or inactivity [4]. Other studies have demonstrated similar findings in rodents with a greater emphasis on skeletal muscle insulin resistance than on myocardial insulin resistance [5]. However, myocardial insulin resistance may be of clinical importance, given the preference for stressed heart to increase glucose utilization and reduce non-esterifed fatty acids (NEFA) oxidation [6]. 
Our laboratory has determined that the cellular basis for myocardial insulin resistance in senescent beagles is associated with mitochondrial abnormalities leading to accumulation of unoxidized NEFA in cardiac myocytes [4]. The mitochondrial abnormalities include decreased expression of key regulators of oxidative phosphorylation including mitochondrial cytochrome oxidase-1 (MCO) and uncoupling protein-3 (UCP-3) [6]. Others have shown that senescent cardiac mitochondria have increased generation of reactive oxygen species leading to peroxidation of key mitochondrial proteins $[7,8]$ predisposing to mitochondrial swelling and disruption. Moreover, in the setting of advanced age, mitochondrial biogenesis, myocyte energetics and cell survival may be compromised [9-11], contributing to an increased risk of heart failure in this population [12].

Therefore, new strategies designed to improve mitochondrial function and restore myocardial insulin resistance in older patients may prove cardio-protective. One such candidate is glucagon-like peptide -1 (GLP-1 [7-36] amide), an incretin hormone that has shown to have potential cardiovascular benefits beyond glycemic control [13-18]. We have previous demonstrated that GLP-1 [7-36] amide was associated with increased insulin action and improved mitochondrial function in young dogs with pacing induced cardiomyopathy [19]. Accordingly, the purpose of the present study was to determine if aging alone predisposes to an accelerated course of dilated cardiomyopathy (DCM) induced by rapid pacing in the absence of conventional cardiovascular risks. A second goal was to determine if myocardial insulin responsiveness could be restored in the senescent myocardium through treatment with GLP-1 (7-36) amide. A third goal was to determine whether preservation of mitochondrial proteins and restoration of myocardial insulin responsiveness would protect the older beagles from an accelerated course of DCM when exposed to a similar pacing stress.

\section{Methods}

Eight young (Young-Control; age 3 years) and 16 old (10-12 years) beagles, weighing 14-18 kg were used in the present study. Figure 1 summarizes the study design. Animal age was confirmed through dental examinations by the veterinary staff. All dogs were carefully screened for all disease known to occur commonly in canines and studied in accordance with the "Guide for the Care and Use of Laboratory Animal Resources" [DHHS Publication No (NIH) 86-23, Revised 1996] and the guidelines of the Institutional Animal Care and Use Committees of the University of Pennsylvania.

\section{Acclimation and surgical instrumentation}

The animals were acclimated to the research laboratory for 6 weeks prior to surgical instrumentation. They were fed a standard chow once daily with a fixed carbohydrate and fat content, and underwent a supervised exercise regimen on a treadmill each day for 30 minutes four times per week for 6 weeks prior to surgical instrumentation as previously described [4].

All dogs underwent sterile surgical instrumentation as previously described $[15,20,21]$. The dogs were allowed to recover from the surgical procedure for 7 days, during which time they were treated with analgesics and antibiotics and trained to rest quietly on the experimental table in a conscious, unrestrained state.

\section{GLP-1 (7-36) amide intervention protocol}

After 4 weeks of training, the older dogs were randomized to receive either GLP-1 (7-36) amide though a continuous intravenous infusion at a dose of $2.5 \mathrm{pmol} / \mathrm{kg} /$ min (Old + GLP-1; $\mathrm{n}=7$ ) or saline ( $3 \mathrm{ml} /$ day) control (Old-Control; $\mathrm{n}=9$ ) using a MiniMed infusion system. The GLP-1 (7-36) amide treatment was initiated 2 weeks prior to surgery and was continued through surgery, recovery ( 1 week) and during the rapid pacing stimulus for

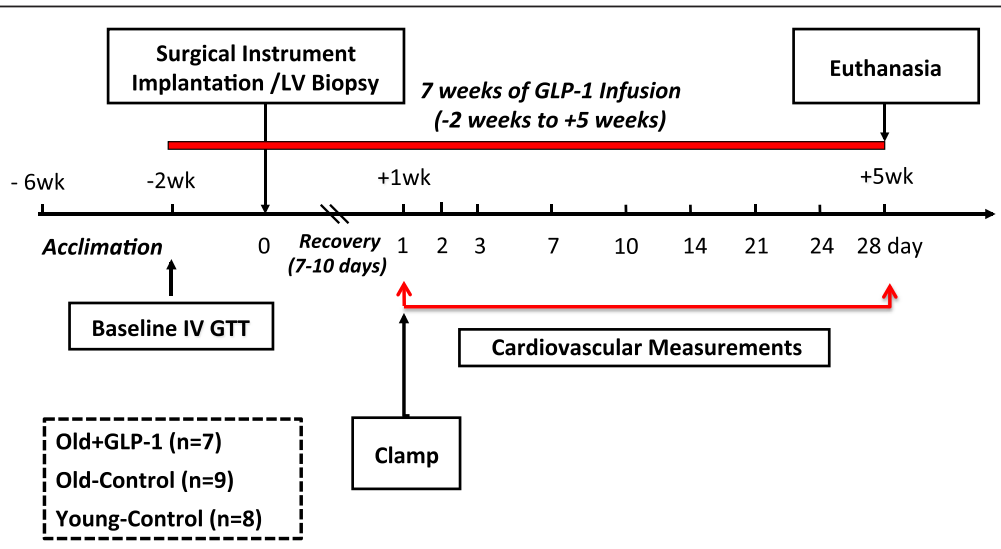

Figure 1 Schematic illustration of the study design and time points for assessment. LV, left ventricle; IV GTT, intravenous glucose tolerance test; Clamp, hyperinsulinemic-euglycemic clamp. 
28 days (Figure 1). Synthetic GLP-1 was mixed in $2.8 \mathrm{ml}$ of normal saline and $0.2 \mathrm{ml}$ of fresh plasma prepared from each animal as previously described [15]. A 99\% pure, pyrogen-free and sterile, single lot of GLP-1 (7-36) amide synthesized in the protein/peptide core facility of the Massachusetts General Hospital was used in this study. Net peptide content was used for all calculations.

\section{Metabolic determinations}

All metabolic parameters were measured at $8 \mathrm{am}$, following an overnight fast. After 4 weeks of training, all dogs underwent baseline blood sampling and an intravenous glucose challenge $(250 \mathrm{mg} / \mathrm{kg}$ IV with $5-10 \mathrm{mi}-$ nute sampling of glucose and insulin for 60 minutes) to determine the magnitude of whole body insulin resistance between young and old beagles prior to exposure to GLP-1. In addition, plasma norepinephrine, insulin, glucagon, adiponectin, non-esterified fatty acids (NEFA), and glucose were measured as previously described [20].

Additionally, whole body and myocardial insulin sensitivity was assessed using the hyperinsulinemic-euglycemic clamp after surgical instrumentation and prior to the pacing insult to assess the effects of 3 weeks of GLP-1 treatment $[15,19]$. Briefly, in the fasting state, a primed, constant infusion of insulin $\left(480 \mathrm{pmol} \cdot \mathrm{m}^{-2} \cdot \mathrm{min}^{-1}\right)$ was administered for 120 minutes to create a steady state concentration of plasma insulin ( 1000 pmol/L). Arterial glucose concentrations were measured every 5 minutes and glucose was infused to maintain plasma glucose concentrations at $5 \mathrm{mmol} / \mathrm{L} \pm 5 \%$. Myocardial glucose and NEFA balance and coronary blood flow were sampled every 15 minutes to determine myocardial glucose uptake. Trans-myocardial substrate balance was calculated as the difference between arterial and coronary sinus content. Basal myocardial substrate uptake was calculated as the product of myocardial substrate balance and coronary blood flow (CBF) [15,19].

\section{Induction of dilated cardiomyopathy and hemodynamic measurements}

After baseline metabolic and hemodynamic measurements, all animals underwent rapid right ventricular pacing using a customized pacemaker at 240 beats/ minute. The rapid pacing was confirmed daily. Animals underwent hemodynamic evaluation at baseline (prior to pacing), daily for the first 3 days after pacing and then every 3 days for the next 28 days or until pre-specified hemodynamic parameters indicative of advanced DCM were reached. Advanced DCM was defined by the presence of depressed LV contractility (LVdP/dt) $<1500 \mathrm{mmHg} / \mathrm{sec}$, increased LV end-diastolic pressure (LVEDP) > $30 \mathrm{mmHg}$, reduced cardiac output $(\mathrm{CO})<1.8 \mathrm{~L} / \mathrm{min}$, and increased LV end-diastolic dimensions (LVEDD) $>45 \mathrm{~mm}$. In addition, stroke volume (SV), and myocardial oxygen consumption $\left(\mathrm{MVO}_{2}\right)$ (product of the left circumflex CBF and the myocardial arterio-venous $\mathrm{O}_{2}$ content difference) were calculated. Coronary flow reserve (maximal coronary blood flow in response to adenosine- resting CBF, $\mathrm{ml} / \mathrm{min}$ ) was determined before and after the development of DCM.

\section{Mitochondrial isolation}

LV myocardial biopsy for isolation of intrafibrillar mitochondria (IFM) was performed at baseline during surgical instrumentation. This timing allowed for comparison of mitochondrial proteins between Young and Old-Control and Old + GLP-1 treated beagles. Crude mitochondrial isolates were prepared from canine myocardium using a trypsin digestion procedure as described previously $[4,15]$. Briefly, after confirming the purity of the mitochondrial preparations by the absence of $\mathrm{Na}+\mathrm{K}+$ ATPase activity, isolated mitochondrial samples were re-suspended to a final protein concentration of $0.5 \mu \mathrm{g} / \mathrm{mL}$ in a buffer at a final concentration of $125 \mathrm{mM}$ Tris- $\mathrm{HCl}, \mathrm{pH} 6.8,20 \%$ $(\mathrm{v} / \mathrm{v})$ glycerol, $5 \%(\mathrm{v} / \mathrm{v}) \beta$-mercaptoethanol, and $0.1 \%(\mathrm{w} / \mathrm{v})$ bromphenol blue. Membrane samples for UCP-3, SDHA, and $\mathrm{MCO}$ were subjected to electrophoretic separation by SDS-PAGE $[4,22]$. Proteins resolved were transferred onto PVDF membrane (Immobilon ${ }^{\mathrm{Tx}}-\mathrm{P}^{\mathrm{SQ}}$, Millipore Corp., Bedford, MA) at a constant voltage (100 V) [23]. Nonspecific membrane protein binding sites were blocked [5\% $(\mathrm{w} / \mathrm{v})$ dry milk in Tris-buffered saline with $0.1 \%(\mathrm{v} / \mathrm{v})$ Tween-20 (TTBS)] and then membranes were probed with polyclonal rabbit anti-UCP-3 antibody (1:10,000) (Alpha Diagnostics, San Antonio, TX), or monoclonal mouse anti-MCO antibody $(1: 100,000)$ (Abcam Inc., Cambridge, MA). The immunoreactive proteins were detected by use of an enhanced horseradish peroxidase/ luminol chemiluminescence reaction kit (Perkin Elmer Life Sciences, Boston, MA) and exposed to X-ray film (Hyperfilm $\mathrm{ECL}^{\mathrm{Tm}}$, Amersham Pharmacia Biotech, Piscataway, NJ). Densitometric analysis of the bands was carried out using a Personal Densitometer SI and ImageQuant ${ }^{\mathrm{TM}}$ Software (Molecular Dynamics, Sunnyvale, CA).

Mitochondrial lipid peroxidation was assessed by levels of malondialdehyde (MDA), a marker of lipid oxidation using lipid peroxidation assay kit (Calbiochem, San Diego, CA) as previously described [24]. To prevent sample oxidation, extracts were normalized to $1-1.5 \mathrm{mg} / \mathrm{ml}$ in re-suspension buffer with $5 \mathrm{mM}$ butylated hydroxyl toluene. For each reaction, a 200- $\mu$ l sample/standard was added to $650-\mu \mathrm{l}$ chromogenic reagent and $150 \mu \mathrm{l}$ of $12 \mathrm{~N} \mathrm{HCl}$. After reaction at $45^{\circ} \mathrm{C}$ for $60 \mathrm{~min}$, the samples were cooled at $4^{\circ} \mathrm{C}$ and centrifuged at $10,000 \mathrm{~g}$ for $5 \mathrm{~min}$. The supernatants were collected, and absorbance at $586 \mathrm{~nm}$ was recorded. MDA concentration was calculated using a standard curve. All measurements were performed in duplicate. 


\section{Statistical analysis}

Data are expressed as the mean value \pm SEM. Differences in hemodynamic and metabolic responses between the groups were determined by two-way ANOVA. Where differences were detected over time, a post hoc Student's Newman Keuls's test was performed to determine differences at respective time points. Differences in mitochondrial proteins and metabolic parameters were determined using Student T-test for unpaired data. A Bonferroni correction was used when multiple comparisons were evaluated. A level of $\mathrm{p}<0.05$ was considered statistically significant.

\section{Results}

The effects of age on baseline body mass index and metabolic parameters

Table 1 illustrates the effects of age on body mass index and metabolic parameters after 4 weeks of training and prior to GLP-1 infusion and surgical instrumentation. At baseline, there was no difference in body weight, body mass index or abdominal girth between groups. Fasting plasma glucose levels were normal while plasma insulin levels $(\mathrm{p}<0.01)$ and NEFA levels $(\mathrm{p}<0.001)$ were significantly higher in the Old-Control and Old + GLP-1 groups suggesting insulin resistance. There were no differences in plasma adiponectin or leptin levels. Notably, plasma arterial norepinephrine was also increased $(p<0.001)$ in the Old-Control and Old + GLP-1 groups.

The intravenous glucose challenge in young and older beagles at baseline prior to GLP-1 infusion was associated with a higher peak plasma glucose response in the Old-Control and Old + GLP-1 groups (Figure 2A) and a markedly greater increase in plasma insulin (Figure $2 \mathrm{~B}$ ), suggesting whole body insulin resistance in the OldControl and Old + GLP-1 groups compared to YoungControl. Notably, there was no difference in the degree of whole body insulin resistance or any other baseline parameter between the Old-Control and Old + GLP-1 groups prior to GLP-1 infusion (Table 1).

\section{Age and the effects of GLP-1Infusion on hemodynamic parameters prior to onset of pacing induced DCM}

After 3 weeks of GLP-1 treatment and 7 days from surgical instrumentation (Figure 1), LV and systemic hemodynamics were assessed in all groups (Table 2). There were no significant differences in the LV systolic or end diastolic pressures, $\mathrm{LV} \mathrm{dP} / \mathrm{dt}$, or $\mathrm{LV}$ dimensions between groups. Old-Control beagles had impaired LV isovolumic relaxation time constants (tau: $25 \pm 2$ vs. $18 \pm 1 \mathrm{msec}, \mathrm{p}<0.001$ ), higher mean arterial pressures $(107 \pm 7$ vs. $89 \pm 3 \mathrm{mmHg}, \mathrm{p}<0.05)$ and systemic vascular resistance $\left(3421 \pm 224\right.$ vs $2649 \pm 267$ dyne-sec-cm ${ }^{-5}$, $\mathrm{p}<0.05)$ compared to Young-Control, but comparable heart rate, cardiac output, and LV ejection fraction. Old-Control dogs had higher resting $\mathrm{MVO}_{2}$ compared to Young-Control $\left(313 \pm 39\right.$ vs $150 \pm 21 \mathrm{mlO}_{2} / \mathrm{min}, \mathrm{p}<$ $0.01)$. GLP-1 treatment improved isovolumic relaxation in Old + GLP-1 compared to Old-Control $(\mathrm{p}<0.05)$. GLP-1 had no significant effects on resting cardiac output or coronary blood flow. Mean arterial pressure, systemic vascular resistance and $\mathrm{MVO}_{2}$ tended to be lower in Old + GLP-1 dogs after 3 weeks of treatment compared to Old-Control, although the differences did not reach statistical significance.

\section{Age predisposes progression of pacing induced DCM}

Figure 3 illustrates the time course of the development of hemodynamically significant dilated cardiomyopathy following the initiation of rapid pacing. $\mathrm{LV} \mathrm{dP} / \mathrm{dt}$ decreased to less than $1,500 \mathrm{mmHg} / \mathrm{sec}$ within 7 days in Old-Control dogs compared to 25 days in Young-Control $(\mathrm{p}<0.001$, Figure 3A). Cardiac output declined to less than $1.7 \mathrm{l} / \mathrm{min}$ within 3 days in Old-Control compared to 28 days in Young-Control $(\mathrm{p}<0.001$, Figure $3 \mathrm{~B})$, while LV end

Table 1 Effects of age on baseline body mass index and metabolic parameters

\begin{tabular}{|c|c|c|c|c|c|c|}
\hline & \multirow{3}{*}{$\begin{array}{l}\text { Young } \\
\text { Control } \\
\mathrm{n}=8\end{array}$} & \multicolumn{5}{|l|}{ Old } \\
\hline & & \multicolumn{2}{|c|}{ Old-Control } & \multicolumn{2}{|c|}{ Old + GLP-1 } & \multirow[b]{2}{*}{$p$ value ** } \\
\hline & & $n=9$ & p value* & $n=7$ & p value* & \\
\hline Age (years) & $3.5 \pm 1$ & $11.2 \pm 1$ & $<0.01$ & $11.9 \pm 1$ & $<0.01$ & NS \\
\hline $\mathrm{BMI}\left(\mathrm{kg} / \mathrm{w}^{2}\right)$ & $25 \pm 0.6$ & $26 \pm 0.7$ & NS & $27 \pm 1$ & NS & NS \\
\hline Body Weight (kg) & $15 \pm 3$ & $15 \pm 3$ & NS & $16 \pm 2$ & NS & NS \\
\hline Glucose (mmol/L) & $5.2 \pm 0.2$ & $5.0 \pm 0.2$ & NS & $4.9 \pm 0.3$ & NS & NS \\
\hline NEFA $(\mu \mathrm{mol} / \mathrm{L})$ & $363 \pm 52$ & $897 \pm 67$ & $<0.01$ & $913 \pm 75$ & $<0.01$ & NS \\
\hline Insulin (pmol/L) & $33 \pm 9$ & $110 \pm 13$ & $<0.01$ & $99 \pm 20$ & $<0.01$ & NS \\
\hline Glucagon (pq/ml) & $26 \pm 2$ & $32 \pm 9$ & NS & $38 \pm 8$ & NS & NS \\
\hline Adiponectin $(\mu \mathrm{g} / \mathrm{ml})$ & $2.9 \pm 0.6$ & $2.7 \pm 0.9$ & NS & $2.9 \pm 0.5$ & NS & NS \\
\hline $\mathrm{NE}(\mathrm{pmol} / \mathrm{ml})$ & $56 \pm 13$ & $396 \pm 52$ & $<0.01$ & $422 \pm 40$ & $<0.01$ & NS \\
\hline
\end{tabular}

Data is presented as Mean \pm SEM; *Compared to young; ${ }^{* *}$ Old-Control compared to Old + GLP-1; Old-Control, old beagles placebo; Old + GLP-1, old beagles GLP-1 treated; BMI, body mass index; NEFA, Non-esterified fatty acids; NE, plasma arterial norepinephrine. 

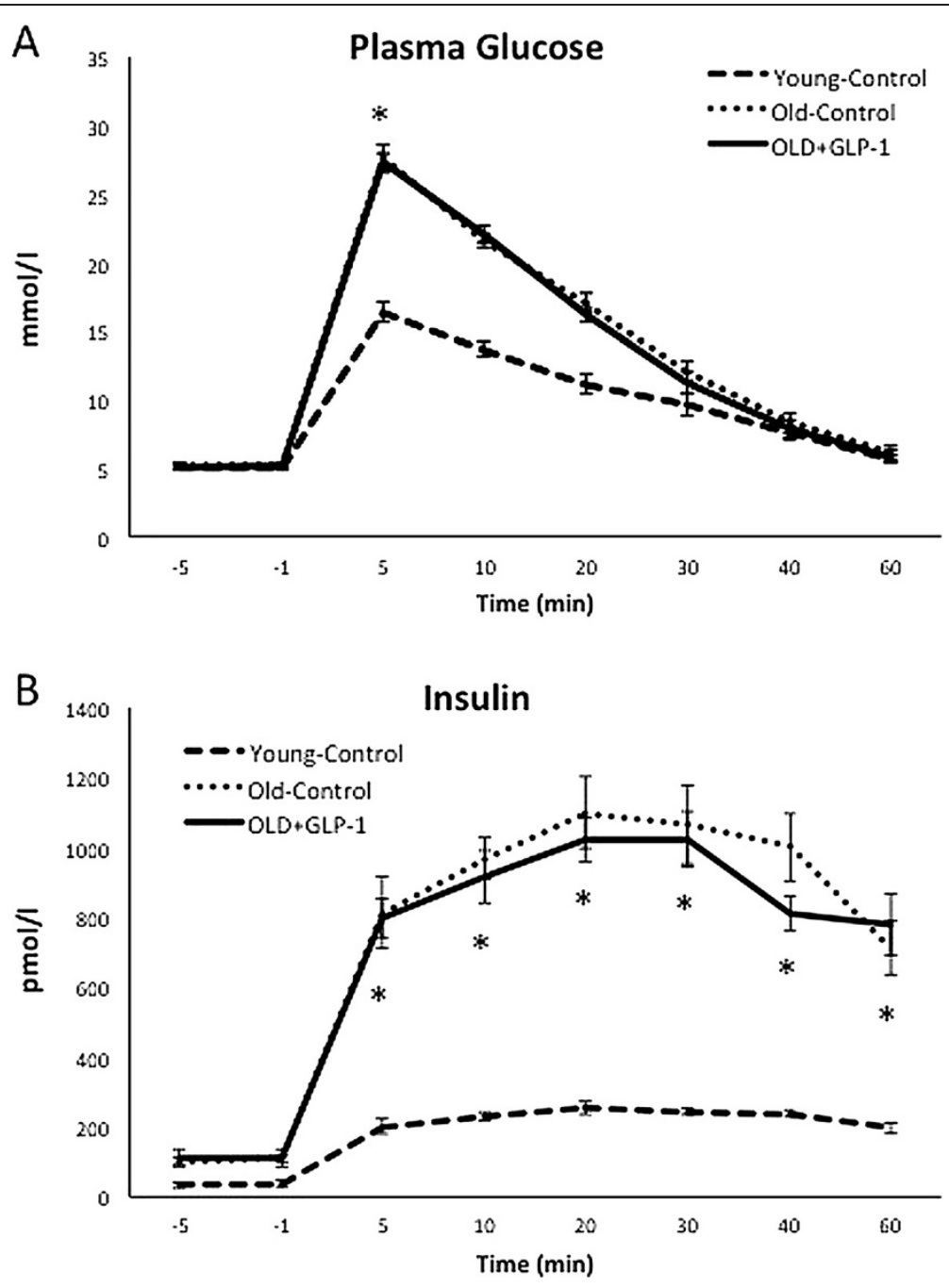

Figure 2 Baseline intravenous glucose challenge 4 weeks after training. Young-Control $(n=8)$, Old-Control $(n=9)$, and Old $+G L P-1(n=7)$ dogs underwent to an intravenous glucose challenge prior to randomization to GLP-1 infusion. (A) Higher peak of plasma glucose response and (B) greater increase in plasma insulin in the older dogs, both suggesting whole body insulin resistance in the older groups compared to Young-Control animals. IV GTT, intravenous glucose tolerance test; * $p<0.01$.

diastolic pressure rose to greater than $30 \mathrm{mmHg}$ within 7 days in Old-Control compared to 28 days in YoungControl $(\mathrm{p}<0.001$, Figure $3 \mathrm{C})$. Finally, LV dilatation occurred within 3 days in Old-Control compared to 28 days in Young-Control $(\mathrm{p}<0.001$, Figure 3D). Notably, 33\% ( $\mathrm{n}=3)$ of the Old-Control dogs died before reaching the pre-specified hemodynamic end point compared to $0 \%$ mortality in the Young-Control at 28 days. Thus, despite comparable baseline hemodynamics, OldControl dogs had a remarkably accelerated course of pacing induced DCM.

\section{GLP-1 infusion restores myocardial substrate uptake in older dogs}

The beneficial effects of GLP-1 infusion on myocardial metabolism were assessed under conditions of the hyperinsulinemic-euglycemic clamp. Both basal and insulin stimulated myocardial glucose uptake were reduced in Old-Control dogs (Figure 4A) while basal myocardial NEFA uptake was increased compared to Young-Control (Figure 4B). Hyperinsulinemia suppressed myocardial NEFA uptake and to a greater extent in OldControl compared to Young-Control (Figure 4B). In contrast, GLP-1 infusion improved basal and insulin stimulated myocardial glucose uptake in Old + GLP-1 and suppressed basal NEFA uptake compared to Old-Control dogs (Figure 4A).

Moreover, GLP-1 infusion had a positive impact on reactive oxygen species and mitochondrial protein expression in Old + GLP-1. Aging was associated with increased cellular and mitochondrial reactive oxygen species (ROS) compared to Young-Control as demonstrated by higher 
Table 2 Aging and GLP-1 on left ventricular and systemic hemodynamics after 3 weeks of GLP-1 treatment and before the onset of DCM

\begin{tabular}{|c|c|c|c|c|c|}
\hline & \multirow{3}{*}{$\begin{array}{l}\text { Young } \\
\text { Control } \\
n=8\end{array}$} & \multicolumn{4}{|l|}{ Old } \\
\hline & & \multicolumn{2}{|c|}{ Old-Control } & \multicolumn{2}{|l|}{ Old + GLP-1 } \\
\hline & & $\mathrm{n}=9$ & p value* & $n=7$ & p value ${ }^{*}$ \\
\hline LVESP $(\mathrm{mmHg})$ & $118 \pm 4$ & $132 \pm 10$ & NS & $130 \pm 10$ & NS \\
\hline LVEDP $(\mathrm{mmHg})$ & $9 \pm 1$ & $11 \pm 2$ & NS & $10 \pm 3$ & NS \\
\hline $\mathrm{LV} \mathrm{dP} / \mathrm{dt}(\mathrm{mmHg} / \mathrm{sec})$ & $2881 \pm 121$ & $2801 \pm 176$ & NS & $2912 \pm 200$ & NS \\
\hline LV tau (msec) & $18 \pm 1$ & $25 \pm 2$ & $<0.01$ & $19 \pm 1 \dagger$ & NS \\
\hline MAP ( $\mathrm{mmHg})$ & $89 \pm 3$ & $107 \pm 7$ & $<0.05$ & $102 \pm 5$ & $<0.05$ \\
\hline Heart Rate (min-1) & $90 \pm 4$ & $101 \pm 10$ & NS & $99 \pm 12$ & NS \\
\hline $\mathrm{CO}(\mathrm{L} / \mathrm{min})$ & $2.7 \pm 0.3$ & $2.5 \pm 0.3$ & NS & $2.5 \pm 0.4$ & NS \\
\hline LVEF (\%) & $54 \pm 4$ & $50 \pm 5$ & NS & $51 \pm 4$ & NS \\
\hline SVR (dyne-sec-cm-5) & $2649 \pm 267$ & $3421 \pm 224$ & $<0.05$ & $3164 \pm 123$ & NS \\
\hline $\mathrm{MVO}_{2}(\mathrm{ml} \mathrm{O} / \mathrm{min})$ & $150 \pm 21$ & $313 \pm 39$ & $<0.01$ & $243 \pm 22+$ & $<0.01$ \\
\hline Coronary Flow (ml/min) & $25 \pm 3$ & $26 \pm 4$ & NS & $27 \pm 4$ & NS \\
\hline LVEDD (mm) & $40 \pm 3$ & $40 \pm 3$ & NS & $41 \pm 3$ & NS \\
\hline $\operatorname{LVESD}(\mathrm{mm})$ & $33 \pm 2$ & $34 \pm 3$ & NS & $33 \pm 3$ & NS \\
\hline
\end{tabular}

Data is presented as Mean \pm SEM; * Compared to young; $\uparrow \mathrm{p}<0.05$ compared to Old-Control; Old-Control, old dogs placebo; Old + GLP-1, old dogs GLP-1 treated; LVESP, left ventricle end-systolic pressure; LVEDP, left ventricle end-diastolic pressure; LV dP/dt, left ventricle rate of rise of left ventricular pressure; tau, isovolumic

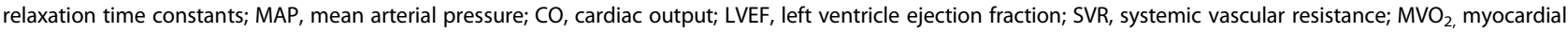
oxygen consumption, LVEDD, left ventricle end-diastolic diameter; LVESD, left ventricle end-systolic diameters.

levels of MDA, a marker of lipid peroxidation, in the OldControl dogs (Figure 5A). Aging was also associated with decreased mitochondrial expression of UCP-3 and MCO in cardiomyocytes compared to Young-Control (Figure 5B). Interestingly, GLP-1 infusion increased mitochondrial protein expression and decreased MDA abundance compared to Old-Control suggesting that GLP-1 may ameliorate underlying mitochondrial protein abnormalities and reduce ROS observed in the cardiomyocytes with aging.

\section{GLP-1 infusion preserves coronary flow reserve}

There were no differences in basal coronary blood flow responses between groups either before (Figure 6A) or after the development of DCM (Figure 6B). However, the vasodilator response to hyperinsulinemia was markedly attenuated in Old-Control dogs at baseline and abolished completely following the development of DCM (Figure 6B). Notably, Old + GLP-1 dogs demonstrated preserved coronary vasodilator response to hyperinsulinemia in the basal state, but not following the development of advanced DCM (Figure 6A and B). Similarly, the coronary blood flow response to adenosine was reduced in Old-Control dogs both under basal conditions and following DCM (Figure 6C and D). Interestingly, Old + GLP-1 dogs showed preserved flow reserve under basal conditions and better preservation of flow reserve following the development of DCM compared to OldControl (Figure 6C and D).
GLP-1 protects old beagles from an accelerated course of DCM

GLP-1 infusion and the associated improvement in myocardial insulin action, mitochondrial protein expression and coronary flow reserve was associated with a prolonged course of dilated cardiomyopathy and increased survival in Old + GLP-1 compared to Old-Control (Figure 7). LV $\mathrm{dP} / \mathrm{dt}$ decreased to less than $1,500 \mathrm{mmHg} / \mathrm{sec}$ within 7 days in Old-Control dogs with myocardial insulin resistance compared to 24 days in Old + GLP-1 dogs ( $<<0.01$, Figure 7A). Cardiac output declined to less than $1.7 \mathrm{l} / \mathrm{min}$ within 3 days in Old-Control compared to 28 days in Old + GLP-1 dogs $(\mathrm{p}<0.01$, Figure $7 \mathrm{~B})$, while LV end diastolic pressure rose to greater than $30 \mathrm{mmHg}$ within 7 days in Old-Control compared to 21 days in Old + GLP-1 dogs ( $<<0.01$, Figure $7 C$ ). Finally, LV dilatation occurred within 3 days in Old-Control compared to 28 days in Old + GLP-1 dogs $(\mathrm{p}<0.001$, Figure 7D). Interestingly, Old + GLP-1 dogs survived to 28 days similar to that seen in Young-Control, but in contrast to the premature mortality observed in Old-Control. Compare to Young-Control (Figure 3) Old + GLP-1 dogs did not differ statistically in any of the hemodynamic parameters during the progression of pacing induced DCM.

\section{Discussion}

In the present study, we observed that old dogs with myocardial insulin resistance developed an accelerated course 

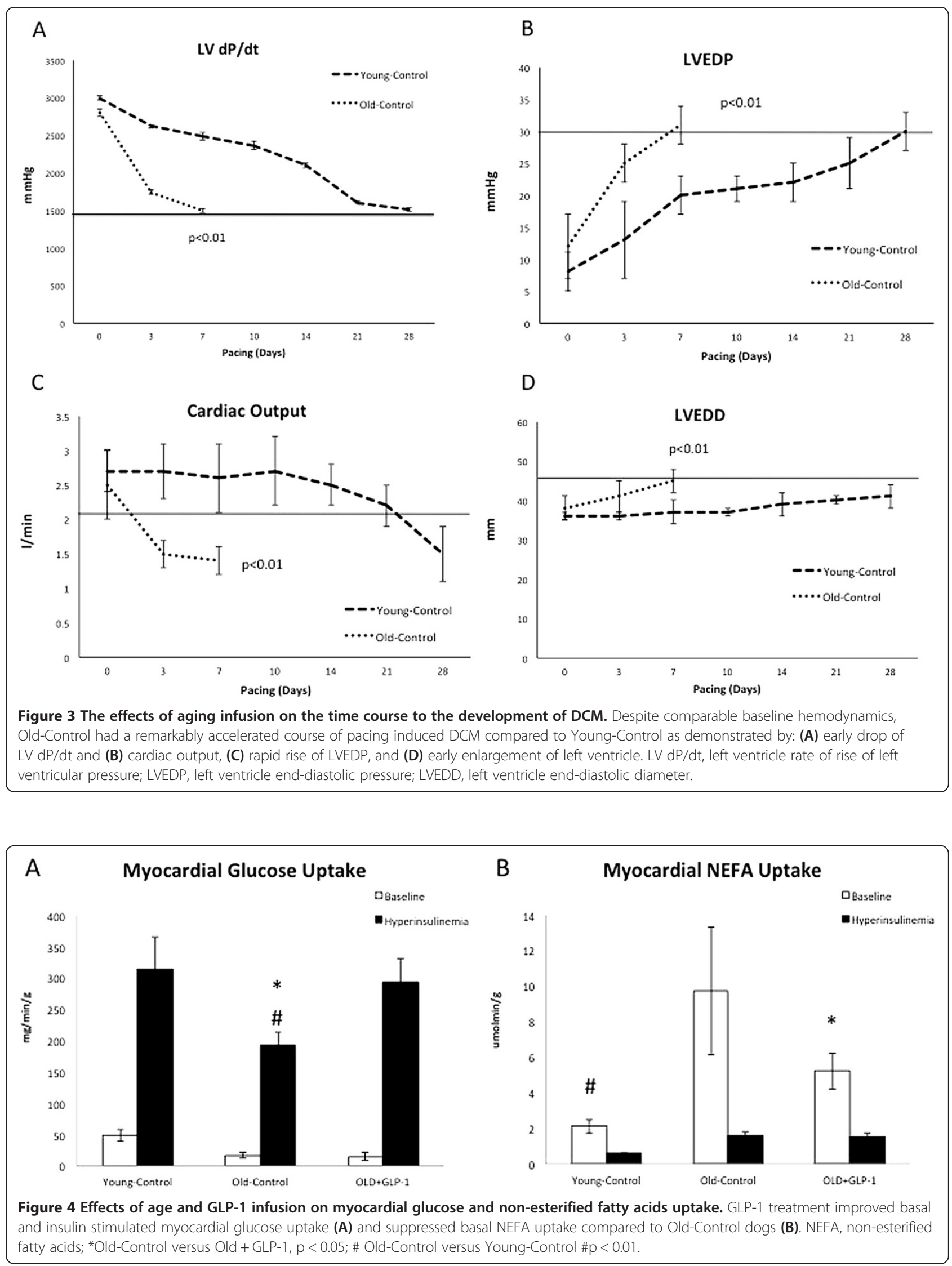

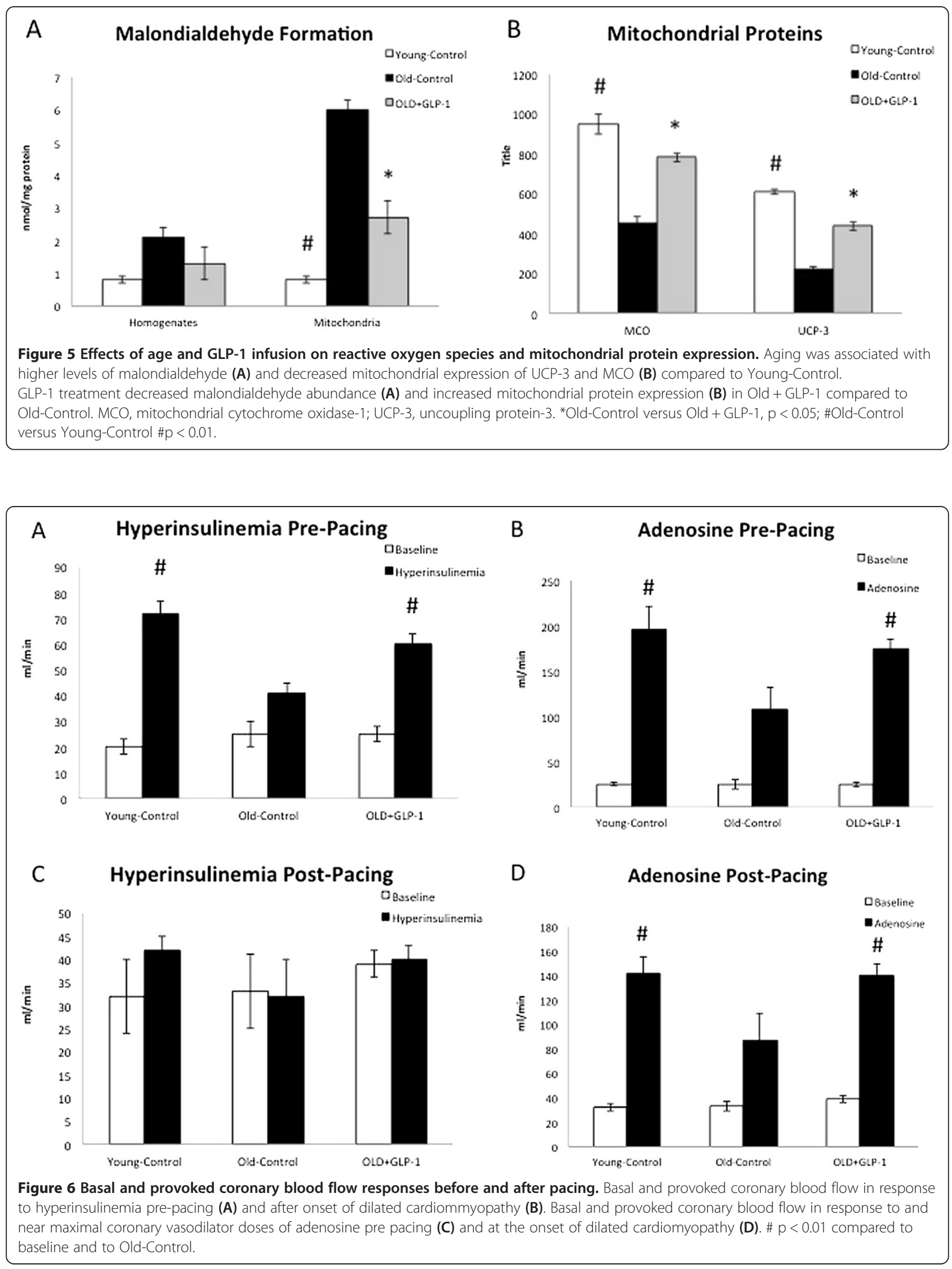


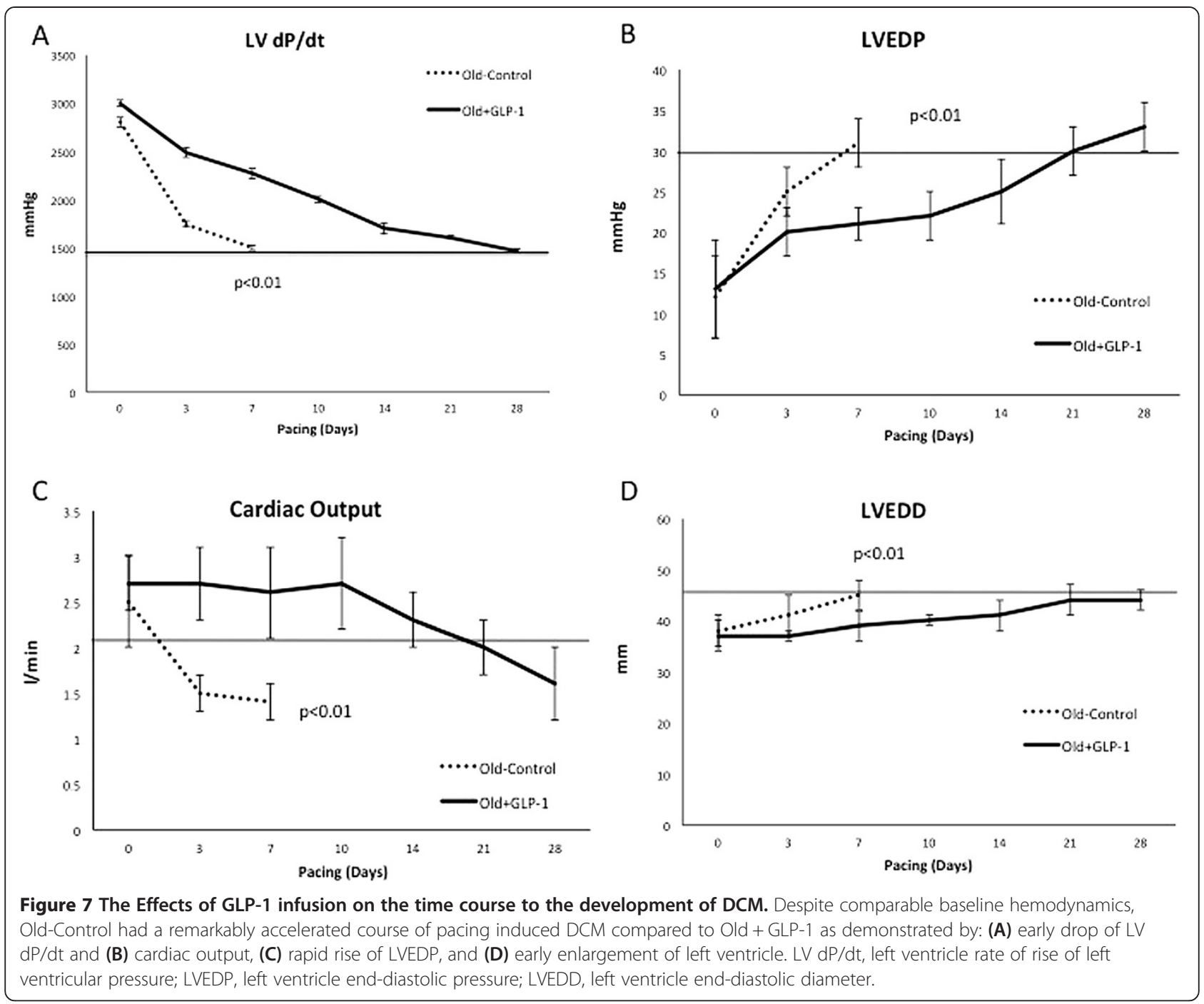

of dilated cardiomyopathy in response to rapid ventricular pacing compared to Young-Control. Treatment with a continuous infusion of GLP-1(7-36) amide improved myocardial insulin sensitivity, reduced myocardial mitochondrial oxidative stress, preserved expression of key mitochondrial proteins associated with oxidative balance (UCP-3) and mitochondrial respiration (MCO), and preserved coronary flow reserve culminating in an improved clinical course and reduced mortality following rapid pacing. These findings underscore the role of mitochondrial dysfunction and associated impaired myocardial insulin responsiveness in the progression of heart failure in advanced age.

Aging has been associated with altered mitochondrial protein expression and reduced energetic reserve in studies of skeletal muscle $[25,26]$. These alterations have been linked to the cellular mechanisms of insulin resistance, mediated through increased accumulation of NEFA [4], features which have been associated with increased reactive oxygen species production in senescent mitochondria [27]. Under conditions in which ROS production exceeds anti-oxidative capacity, increased UCP-3 activity dissipates the electromotive force and reduces mitochondrial ROS production [28]. A consequence of the decreased transmenbrane potential $(\Delta \varphi)$ is reduced electromotive force for ATP generation, which may become relevant under circumstances of increased energetic demand, as occurs with pacing induced heart failure $[15,29]$. When these physiological adaptive responses are further compromised by alterations in components of the electron transfer chain, such as MCO or decreased expression or function of UCP-3, further ROS generation leads to lipid peroxidation and eventually mitochondrial permeability transition, and ultimately necrotic cell death $[7,22]$.

In the present study we observed myocardial insulin resistance and altered mitochondrial ROS generation in association with decreased MCO, and UCP-3 expression 
in intrafibrillar myocardial mitochondria in older beagles. We focused on IFM as the most relevant component given their role in myocardial contractility and because age-associated changes seem to affect IFM preferentially [30]. Decreased UCP-3 expression would be expected to further impair the mitochondrial capacity to mitigate ROS leading to lipid peroxidation and further mitochondrial dysfunction [31].

We have shown previously that GLP-1 infusion improves cardiovascular function when administered for 48 hours to young dogs with severe dilated cardiomyopathy [19]. We have also shown that the hemodynamic improvement was associated with both increased myocardial glucose uptake and increased expression of key components of the mitochondrial electron transport chain (ETC.), specifically MCO, the expression of which was significantly reduced in dilated cardiomyopathy. Furthermore, GLP-1 treatment was associated with reduced mitochondrial ROS production and increased UCP-3 expression. UCP-3 has been shown to be an important buffer against excess free radical accumulation within the mitochondrial matrix (29). We have also shown that normal aging in older beagles is associated with similar changes in the absence of heart failure (4). Here, we observe a similar effect of GLP-1 infusion on UCP-3 and $\mathrm{MCO}$ and also observe better preservation of these components following rapid pacing in old animals without baseline heart failure. Together, these salutary changes in mitochondrial protein expression were associated with slowing the progression of heart failure in the GLP-1 treated animals. Thus, both aging and heart failure appear to be associated with impaired mitochondrial function and myocardial glucose utilization and the effects appear to be synergistic.

We have also previously shown that the development of advanced heart failure in conscious dogs is associated with impaired coronary flow and vasodilator reserve in response to coronary vasodilators [20]. Here we demonstrate that aging alone in the presence of myocardial insulin resistance is associated with impaired coronary flow reserve in response to sub-maximal doses of adenosine. Importantly, these data are the first to confirm that GLP-1 treatment improves coronary flow responses to insulin and adenosine. Furthermore, coronary flow reserve was better preserved in advanced heart failure in the Old + GLP-1 compared to Old-Control. This is the first demonstration of a vascular protective effect of GLP-1 on coronary flow reserve in a model of non-ischemic DCM.

There is an extensive literature that has demonstrated the salutary effects of both DPP-4 inhibitors [32] and DPP-4 resistant long acting receptor analogs [33] in mitigating ischemia- reperfusion injury and reducing infarct size in rodent models through a PKA dependent mechanism. These findings underscore the importance of GLP-1 receptor medicated signaling in ischemiareperfusion syndromes. Our findings are the first to document significant salutary effects of GLP-1 (7-36) amide in a large animal model of aging and heart failure. The findings are notable in light of the recent clinical trials data that have suggested that DPP-4 inhibitors increase the risk of heart failure hospitalizations in patients with Type 2 diabetes [34]. A critical difference is the fact that in our study, the native peptide is metabolized to the active metabolite, GLP-1 (9-36), which we [35] have shown to be biologically active, particularly vasoactive. These additive effects of the metabolite are not present with DPP-4 inhibitors or DPP-4 resistant GLP-1 receptor agonists. Secondly, the continuous infusion of the native peptide resulted in steady state pharmacological concentrations of total GLP-1 ( 100 pM) while DPP-4 inhibitors result in physiological levels $(20 \mathrm{pM})$. These differences may not only be relevant to our findings in older beagles but also explain why clinical studies of heart failure patients [16] and post-operative patients [36] have shown benefits with continuous infusions of the native peptide GLP-1 (7-36) amide.

\section{Limitations}

The findings of increased mitochondrial ROS, reduced mitochondrial protein expression, and impaired myocardial insulin resistance were associations that do not prove causality in terms of the accelerated course of DCM in Old-Control. Other cellular process may also be deranged which could contribute to the response. Nonetheless, GLP-1 treatment mitigated the mitochondrial and metabolic abnormalities and protected OldGLP-1against an accelerated course. Secondly, we measured mitochondrial protein expression not function. Additional studies detailing mitochondria abundance and morphology may help to further understand the role of mitochondrial dysfunction in this model and the extent to which GLP-1 may influence mitochondrial biogenesis and autophagy. Thirdly, it took several years to complete this study as the availability of senescent beagles was rate limiting. We began using MDA as a method to assess lipid peroxidation and continued to do so for the purposes of consistency over time. We recognize that currently there may be better quantitative methods of lipid peroxidation quantification. Finally, GLP-1 treatment was associated with improved coronary flow responses, suggesting vascular protective effects of GLP-1. While we cannot ascertain the relative contribution of these favorable changes to the improved clinical outcome in Old + GLP-1 dogs, these data demonstrate that GLP-1 treatment has multiple salutary cardiovascular effects in heart failure beyond glycemic control. 


\section{Conclusions}

Aging and associated mitochondrial dysfunction and insulin resistance predispose to an accelerated course of dilated cardiomyopathy and early mortality. Infusion of GLP-1 (7-36) amide is associated with reduced myocardial mitochondrial ROS and improved myocardial insulin sensitivity and protection against an accelerated course of dilated cardiomyopathy and early mortality in older beagles, suggesting salutary cardiovascular effects in heart failure beyond glycemic control.

\section{Abbreviations}

BMl: Body mass index; Clamp: Hyperinsulinemic-eyglycemic clamp; CO: Cardiac output; CV: Cardiovascular; DCM: Dilated cardiomyopathy; GLP: Glucagon like peptide; IFM: Intrafibrillar mitochondria; IV

GTT: Intravenous glucose tolerance test; LV dP/dt: Left ventricle rate of rise of left ventricular pressure; LV: Left ventricle; LVEDD: Left ventricle end-diastolic diameter; LVEDD: Left ventricle end-diastolic diameter; LVEDP: Left ventricle end-diastolic pressure; LVEF: Left ventricle ejection fraction; LVESD: Left ventricle end-systolic diameters.; MAP: Mean arterial pressure;

MCO: Mitochondrial cytochrome oxidase-1; MIR: Myocardial insulin responsiveness; $\mathrm{MVO}_{2}$ : Myocardial oxygen consumption; NE: Plasma arterial norepinephrine; NEFA: Non-esterified fatty acids; SVR: Systemic vascular resistance; tau: Isovolumic relaxation time constants; UCP-3: Uncoupling protein-3.

\section{Competing interests}

Dr Shannon is the founder of Ventrigen, LLC, and has received research support from Pfizer and Astra Zeneca/ Bristol Myers Squibb for the study of incretins and DPP-4 inhibitors in CV disease states in animals. No industry based products or support were provided for these studies.

\section{Authors' contributions}

MC, YTS assisted in the conduct of the study. RPS designed the study. MC, FSA, YTS, and RPS assisted in the analysis and interpretation of the data. FSA, RPS contributed to the writing of the study.

\section{Funding sources}

The study was supported through R01 AG 023125NIH/NIA.

\section{Author details}

${ }^{1}$ Departments of Medicine, University of Pennsylvania Perelman School of Medicine, Philadelphia, PA, USA. Department of Medicine, University of Virginia School of Medicine, Philadelphia, PA, USA. ${ }^{3}$ University of Virginia Health System, PO Box 800813, 22908 Charlottesville, VA, USA.

Received: 27 May 2014 Accepted: 19 July 2014

Published online: 31 July 2014

\section{References}

1. Ho KK, Pinsky JL, Kannel WB, Levy D: The epidemiology of heart failure: the Framingham Study. J Am Coll Cardiol 1993, 22:6A-13A.

2. Ho KK, Anderson KM, Kannel WB, Grossman W, Levy D: Survival after the onset of congestive heart failure in Framingham Heart Study subjects. Circulation 1993, 88:107-115.

3. Oxenham $\mathrm{H}$, Sharpe $\mathrm{N}$ : Cardiovascular aging and heart failure. Eur $\mathrm{J}$ Heart Fail 2003, 5:427-434.

4. Bhashyam S, Parikh P, Bolukoglu H, Shannon AH, Porter JH, Shen YT, Shannon RP: Aging is associated with myocardial insulin resistance and mitochondrial dysfunction. Am J Physiol Heart Circ Physiol 2007, 293:H3063-H3071.

5. Torlinska T, Mackowiak P, Nogowski L, Hryniewiecki T, Witmanowski H, Perz M, Md E, Nowak KW: Age dependent changes of insulin receptors in rat tissues. J Physiol Pharmacol 2000, 51:871-881.

6. Luptak I, Yan J, Cui L, Jain M, Liao R, Tian R: Long-term effects of increased glucose entry on mouse hearts during normal aging and ischemic stress. Circulation 2007, 116:901-909.
7. Di Lisa F, Bernardi P: Mitochondrial function and myocardial aging: a critical analysis of the role of permeability transition. Cardiovasc Res 2005, 66:222-232

8. Papa S, Skulachev VP: Reactive oxygen species, mitochondria, apoptosis and aging. Mol Cell Biochem 1997, 174:305-319.

9. Lin J, Wu H, Tarr PT, Zhang CY, Wu Z, Boss O, Michael LF, Puigserver P, Isotani E, Olson EN, Lowell BB, Bassel-Duby R, Splegelman BM: Transcriptional co-activator PGC-1 alpha drives the formation of slow-twitch muscle fibres. Nature 2002, 418:797-801.

10. Anderson R, Prolla T: PGC-1alpha in aging and anti-aging interventions. Biochim Biophys Acta 2009, 1790:1059-1066.

11. Loeb LA, Wallace DC, Martin GM: The mitochondrial theory of aging and its relationship to reactive oxygen species damage and somatic mtDNA mutations. Proc Natl Acad Sci U S A 2005, 102:18769-18770.

12. Rich MW: Epidemiology, pathophysiology, and etiology of congestive heart failure in older adults. J Am Geriatr Soc 1997, 45:968-974.

13. Barragan JM, Rodriguez RE, Blazquez E: Changes in arterial blood pressure and heart rate induced by glucagon-like peptide-1-(7-36) amide in rats. Am J Physiol 1994, 266:E459-E466.

14. Green BD, Hand KV, Dougan JE, McDonnell BM, Cassidy RS, Grieve DJ: GLP-1 and related peptides cause concentration-dependent relaxation of rat aorta through a pathway involving KATP and CAMP. Arch Biochem Biophys 2008, 478:136-142.

15. Nikolaidis LA, Elahi D, Hentosz T, Doverspike A, Huerbin R, Zourelias L, Stolarski C, Shen YT, Shannon RP: Recombinant glucagon-like peptide-1 increases myocardial glucose uptake and improves left ventricular performance in conscious dogs with pacing-induced dilated cardiomyopathy. Circulation 2004, 110:955-961.

16. Sokos GG, Bolukoglu H, German J, Hentosz T, Magovern GJ Jr, Maher TD, Dean DA, Bailey SH, Marrone G, Benckart DH, Elahi D, Shannon RP: Effect of glucagon-like peptide-1 (GLP-1) on glycemic control and left ventricular function in patients undergoing coronary artery bypass grafting. Am J Cardiol 2007, 100:824-829.

17. Nystrom T, Gonon AT, Sjoholm A, Pernow J: Glucagon-like peptide-1 relaxes rat conduit arteries via an endothelium-independent mechanism. Regul Pept 2005, 125:173-177.

18. Yamamoto H, Lee CE, Marcus JN, Williams TD, Overton JM, Lopez ME, Hollenberg AN, Baggio L, Saper CB, Drucker DJ, Elmquist JK: Glucagon-like peptide-1 receptor stimulation increases blood pressure and heart rate and activates autonomic regulatory neurons. J Clin Invest 2002, 110:43-52.

19. Bhashyam S, Fields AV, Patterson B, Testani JM, Chen L, Shen YT, Shannon RP: Glucagon-like peptide-1 increases myocardial glucose uptake via p38alpha MAP kinase-mediated, nitric oxide-dependent mechanisms in conscious dogs with dilated cardiomyopathy. Circ Heart Fail 2010, 3:512-521.

20. Nikolaidis LA, Sturzu A, Stolarski C, Elahi D, Shen YT, Shannon RP: The development of myocardial insulin resistance in conscious dogs with advanced dilated cardiomyopathy. Cardiovasc Res 2004, 61:297-306.

21. Nikolaidis LA, Doverspike A, Hentosz T, Zourelias L, Shen YT, Elahi D, Shannon RP: Glucagon-like peptide-1 limits myocardial stunning following brief coronary occlusion and reperfusion in conscious canines. J Pharmacol Exp Ther 2005, 312:303-308.

22. Morino K, Petersen KF, Dufour S, Befroy D, Frattini J, Shatzkes N, Neschen S, White MF, Bilz S, Sono S, Pypaert M, Shulman Gl: Reduced mitochondrial density and increased IRS-1 serine phosphorylation in muscle of insulin-resistant offspring of type 2 diabetic parents. J Clin Invest 2005, 115:3587-3593.

23. Towbin H, Staehelin T, Gordon J: Electrophoretic transfer of proteins from polyacrylamide gels to nitrocellulose sheets: procedure and some applications. Proc Natl Acad Sci U S A 1979, 76:4350-4354.

24. Esterbauer $\mathrm{H}$, Cheeseman $\mathrm{KH}$ : Determination of aldehydic lipid peroxidation products: malonaldehyde and 4-hydroxynonenal. Methods Enzymol 1990, 186:407-421.

25. Conley KE, Esselman PC, Jubrias SA, Cress ME, Inglin B, Mogadam C, Schoene RB: Ageing, muscle properties and maximal $\mathrm{O}(2)$ uptake rate in humans. J Physiol 2000, 526(Pt 1):211-217.

26. Conley KE, Jubrias SA, Esselman PC: Oxidative capacity and ageing in human muscle. J Physiol 2000, 526(Pt 1):203-210.

27. Petersen KF, Befroy D, Dufour S, Dziura J, Ariyan C, Rothman DL, DiPietro L, Cline GW, Shulman Gl: Mitochondrial dysfunction in the elderly: possible role in insulin resistance. Science 2003, 300:1140-1142. 
28. Murphy $E$, Steenbergen C: Mechanisms underlying acute protection from cardiac ischemia-reperfusion injury. Physiol Rev 2008, 88:581-609.

29. Lionetti V, Stanley WC, Recchia FA: Modulating fatty acid oxidation in heart failure. Cardiovasc Res 2011, 90:202-209.

30. Lesnefsky EJ, Moghaddas S, Tandler B, Kerner J, Hoppel CL: Mitochondrial dysfunction in cardiac disease: ischemia-reperfusion, aging, and heart failure. J Mol Cell Cardiol 2001, 33:1065-1089.

31. Brand MD, Esteves TC: Physiological functions of the mitochondrial uncoupling proteins UCP2 and UCP3. Cell Metab 2005, 2:85-93.

32. Hausenloy DJ, Whittington HJ, Wynne AM, Begum SS, Theodorou Li Riksen N, Mocanu MM, Yellon DM: Dipeptidyl peptidase-4 inhibitors and GLP-1 reduce myocardial infarct size in a glucose-dependent manner. Cardiovasc Diabetol 2013, 12:154.

33. Bao W, Holt LJ, Prince RD, Jones GX, Aravindhan K, Szapacs M, Barbour AM, Jolivette LJ, Lepore JJ, Willette RN, DeAngelis E, Jucker BM: Novel fusion of GLP-1 with a domain antibody to serum albumin prolongs protection against myocardial ischemia/reperfusion injury in the rat. Cardiovasc Diabetol 2013, 12:148.

34. Scirica BM, Bhatt DL, Braunwald E, Steg PG, Davidson J, Hirshberg B, Ohman P, Frederich R, Wiviott SD, Hoffman EB, Cavender MA, Udell JA Desai NR, Mosenzon O, McGuire DK, Ray KK, Leiter LA, Raz I, Savor-Timi Steering Committee Investigators: Saxagliptin and cardiovascular outcomes in patients with type 2 diabetes mellitus. N Engl J Med 2013, 369:1317-1326.

35. Nikolaidis LA, Elahi D, Shen YT, Shannon RP: Active metabolite of GLP-1 mediates myocardial glucose uptake and improves left ventricular performance in conscious dogs with dilated cardiomyopathy. Am J Physiol Heart Circ Physiol 2005, 289:H2401-H2408.

36. Galiatsatos P, Gibson BR, Rabiee A, Carlson O, Egan JM, Shannon RP, Andersen DK, Elahi D: The glucoregulatory benefits of glucagon-like peptide-1 (7-36) amide infusion during intensive insulin therapy in critically ill surgical patients: a pilot study. Crit Care Med 2014, 42:638-645.

doi:10.1186/s12933-014-0115-x

Cite this article as: Chen et al: GLP-1 (7-36) amide restores myocardial insulin sensitivity and prevents the progression of heart failure in senescent beagles. Cardiovascular Diabetology 2014 13:115.

\section{Submit your next manuscript to BioMed Central and take full advantage of:}

- Convenient online submission

- Thorough peer review

- No space constraints or color figure charges

- Immediate publication on acceptance

- Inclusion in PubMed, CAS, Scopus and Google Scholar

- Research which is freely available for redistribution 